\title{
Inelastic Light Scattering Spectroscopy in Si/SiGe Nanostructures: Strain, Chemical Composition and Thermal Properties
}

\author{
L. Tsybeskov ${ }^{1 *}$, S. A. Mala ${ }^{1}$, X. Wang ${ }^{1}$, J.-M. Baribeau ${ }^{2}$, X. $\mathrm{Wu}^{2}$ and D. J. Lockwood ${ }^{2}$ \\ ${ }^{1}$ Department of Electrical and Computer Engineering, New Jersey Institute of Technology, \\ Newark, NJ 07102, USA \\ ${ }^{2}$ National Research Council, Ottawa, ON KIA 0R6, Canada
}

\begin{abstract}
We present a review of recent studies of inelastic light scattering spectroscopy in two types of $\mathrm{Si} / \mathrm{SiGe}$ nanostructures: planar superlattices and cluster (dot) multilayers including first- and second-order Raman scattering, polarized Raman scattering and low-frequency inelastic light scattering associated with folded acoustic phonons. The results are used in semi-quantitative analysis of chemical composition, strain and thermal conductivity in these technologically important materials for electronic and optoelectronic devices.
\end{abstract}

Keywords: A. Nanostructures; B. Molecular Beam Epitaxy; D. Inelastic Light Scattering; E. Raman Scattering

*Corresponding author: leonid.tsybeskov@njit.edu 


\section{Introduction}

Inelastic light scattering is an important characterization technique providing a great deal of information about the structural and electronic properties of $\mathrm{Si} / \mathrm{SiGe}$ nanostructures [1-5]. A light scattering event in semiconductor nanostructures involves a variety of phonons and produce additional spectral peaks with wavenumbers between bulk acoustic phonons and optical phonons [6]. In Si/SiGe nanostructures, similar to bulk SiGe alloys, the Raman spectrum is composed of three major bands with a Si-like $(\mathrm{Si})$ peak at $\sim 500 \mathrm{~cm}^{-1}$, an alloy-like (SiGe) peak at $\sim 400 \mathrm{~cm}^{-1}$, a Ge-like (Ge) peak at $\sim 300 \mathrm{~cm}^{-1}$, and weaker Raman features located between the three major peaks $[1-5,7,8]$. These weaker Raman features are attributed to local vibration modes (e.g., Si-Si in the presence of a Ge atom, etc.) and various overtones [6, 9]. Light scattering at low wavenumbers $\left(<100 \mathrm{~cm}^{-1}\right)$ is related to processes associated with various acoustic phonons, and second-order Raman scattering produces multiple overlapping peaks located between 600 and $1200 \mathrm{~cm}^{-1}$ [6]. Thus, in Si/SiGe nanostructures the entire spectral region of $0-1200 \mathrm{~cm}^{-1}$ is covered by multiple Raman peaks, and these peaks exhibit strong dependence on growth conditions, strain, temperature and chemical composition.

The intensity of the Raman signal is proportional to the Raman cross-section and the scattering volume, which is related to the light penetration depth and hence the optical absorption coefficient. Resonant Raman scattering (RRS) is associated with significant changes in the Raman cross section, which are directly related to the joint density of states in the electronic bands of bulk materials or nanostructures. While crystalline Si (c-Si) does not exhibit any resonances within the entire visible spectrum, c-Ge has a well-known resonance around $2.2 \mathrm{eV}$ associated with $\mathrm{E}_{1}$ and $\mathrm{E}_{1}+\Delta_{1}$ electronic transitions in the L direction of the Brillouin zone [6]. Thus, in $\mathrm{Si} / \mathrm{SiGe}$ nanostructures the Raman signal intensity as a function of the excitation light photon energy exhibits a broad peak around 2.2-2.5 eV [10-11]. The optical polarization dependence of the Raman scattering intensity is defined by the Raman tensors [6]. In Si/SiGe nanostructures, this technique has been successfully used to detect various imperfections in epitaxially grown samples, including inhomogeneous strain [12-14].

This review is intended to cover the following topics: 
1. Inelastic light scattering in various $\mathrm{Si} / \mathrm{SiGe}$ nanostructures including processes associated with acoustic and optical phonons.

2. Analysis of strain and composition in $\mathrm{Si} / \mathrm{SiGe}$ nanostructures using light-scattering spectroscopy.

3. Evaluation of $\mathrm{Si} / \mathrm{SiGe}$ nanostructure thermal properties using Raman scattering.

4. Application of polarized Raman scattering in detecting strain in $\mathrm{Si} / \mathrm{SiGe}$ nanostructures.

\section{Growth and structural properties of $\mathrm{Si} / \mathrm{SiGe}$ nanostructures: Superlattices and cluster multilayers.}

$\mathrm{Si} / \mathrm{SiGe}$ superlattices (SLs) are formed using alternating thin layers of $\mathrm{Si}$ and $\mathrm{Si}_{1-\mathrm{x}} \mathrm{Ge}_{\mathrm{x}}$ with $\mathrm{x}<0.5$ grown by molecular beam epitaxy (MBE) on (001) Si substrates at a temperature of $\sim 500^{\circ} \mathrm{C}$ (see Fig. 1a and ref. 15). This relatively low growth temperature is chosen to realize dislocation-free pseudomorphic growth, prevent $\mathrm{Si} / \mathrm{SiGe}$ intermixing, and reduce the interface roughness. For a $\mathrm{SiGe}$ layer with thickness below a critical value, the lattice mismatch between $\mathrm{Si}$ and $\mathrm{SiGe}$ is anticipated to be accommodated by a homogeneous tetragonal compression. These compressed SiGe layers are combined with alternating, in most cases strained, Si layers and form $\mathrm{Si} / \mathrm{Si}_{1}$ ${ }_{x} \mathrm{Ge}_{\mathrm{x}} / \mathrm{Si}$ strained-layered SLs.

$\mathrm{Si} / \mathrm{SiGe}$ cluster multilayers (CM) (Fig. 1b) are grown using SiGe thicknesses approaching or above critical values, and the growth of SiGe on $\mathrm{Si}$ requires relief of the elastic energy in the strained SiGe film [16]. At high growth temperature, the adatom diffusion and elastic deformation trigger a transition from two-dimensional to three-dimensional growth modes. This growth mechanism is known as Stranki-Krastanov (S-K) growth, and it is performed at 550$650^{\circ} \mathrm{C}$. In chemical vapor deposition based $\mathrm{S}-\mathrm{K}$ growth, $\mathrm{GeH}_{4}$ diluted in $\mathrm{H}_{2}$ is used and spontaneous intermixing occurs due to thermal and strain-induced diffusion. In this growth mode, most of the SiGe clusters (or islands) have a pyramid/dome-like (uncapped) or pancakelike ( $\mathrm{Si}$ capped) shapes with the Ge concentration gradually increasing toward the cluster core $[17,18]$. 


\section{First order and low-wavenumber Raman scattering in Si/SiGe nanostructures}

Figure 2 shows the Raman spectrum of a Si/Si $i_{1-x} \mathrm{Ge}_{\mathrm{x}} \mathrm{SL}$ (see TEM image on Fig. 1) with the three distinct Raman peaks associated with the $\mathrm{Si}-\mathrm{Si}, \mathrm{Si}-\mathrm{Ge}$ and $\mathrm{Ge}-\mathrm{Ge}$ local bond vibrations. In addition to the major Si-Si Raman peak at $520 \mathrm{~cm}^{-1}$ with FWHM of $5-6 \mathrm{~cm}^{-1}$, a weaker peak at $505-506 \mathrm{~cm}^{-1}$ attributed to strained $\mathrm{Si}$ is found $[5,9,15]$. In both $\mathrm{Si} / \mathrm{SiGe} \mathrm{SLs}$ and S-K CMs, curve fitting indicates that the FWHM of the $505-506 \mathrm{~cm}^{-1}$ peak precisely correlates with the FWHM of the major Raman peak at $520 \mathrm{~cm}^{-1}$ [9]. It was concluded that in both Si/SiGe SLs and $\mathrm{S}-\mathrm{K}$ CMs, the Si layers separating SiGe layers are strained and the strain in SL Si layers is more homogeneous compared to that found in CMs [9]. $\mathrm{Si}_{/} / \mathrm{Si}_{1-\mathrm{x}} \mathrm{Ge}_{\mathrm{x}}$ nanostructures with $\mathrm{x} \geq 0.4$ and thicker SiGe layers usually show the main Raman peak at $\sim 490 \mathrm{~cm}^{-1}$ (Fig. 3) instead of at 520 $\mathrm{cm}^{-1}$, which is attributed to the local Si-Si vibration mode in the presence of Ge [7]. However, if the excitation wavelength is long enough to reach the c-Si substrate, Raman peaks at 520, 508 and $490 \mathrm{~cm}^{-1}$ can be observed (Fig. 3).

Raman spectra associated with Si-Ge and Ge-Ge vibrations are peaked at $417-418 \mathrm{~cm}^{-1}$ and 298$299 \mathrm{~cm}^{-1}$, respectively (Fig. 4). In S-K CM samples, the Si-Ge and Ge-Ge peaks are broader by $\sim 3 \mathrm{~cm}^{-1}$ and are slightly shifted toward lower wavenumbers compared to that in SL samples. In addition, the Raman spectra show weaker and broader peaks at $\sim 250 \mathrm{~cm}^{-1}$ attributed to the resonant Ge vibrational mode and at $438 \mathrm{~cm}^{-1}$ associated with the local $\mathrm{Si}$ vibrational mode in the presence of $\mathrm{Si}$ and $\mathrm{Ge}$, respectively $[19,20]$ These peaks are enhanced in S-K CMs compared to SL samples, most likely due to the higher Ge composition. Figure 5a presents a summary of the reported dependence of the Raman peak wavenumbers associated with $\mathrm{Si}-\mathrm{Si}, \mathrm{Si}-\mathrm{Ge}$ and $\mathrm{Ge}-\mathrm{Ge}$ vibrations on the composition $\mathrm{x}$ in bulk $\mathrm{Si}_{1-\mathrm{x}} \mathrm{Ge}_{\mathrm{x}}$ alloys where there should be no strain [19]. The results are compared to that in $\mathrm{Si} / \mathrm{SiGe}$ nanostructures with various degree of strain (Fig. 5b), and the following composition dependencies are found:

(a) In bulk $\mathrm{Si}_{1-\mathrm{x}} \mathrm{Ge}_{\mathrm{x}}$ alloys, the $\mathrm{Si}-\mathrm{Si}$ Raman peak wavenumber linearly decreases with increasing $\mathrm{x}$, as $\omega_{S i-S i} \approx 520-70 x$. In $\mathrm{Si} / \mathrm{Si}_{1-\mathrm{x}} \mathrm{Ge}_{\mathrm{x}}$ nanostructures, the dependence is much weaker $\omega_{S i-S i} \approx 520-30 x$. 
(b) In bulk $\mathrm{Si}_{1-\mathrm{x}} \mathrm{Ge}_{\mathrm{x}}$ alloys, the $\mathrm{Ge}-\mathrm{Ge}$ Raman peak wavenumber linearly increases with increasing $\mathrm{x}, \omega_{\mathrm{Ge}-\mathrm{Ge}} \approx 280+20 x$. In $\mathrm{Si} / \mathrm{Si}_{1-\mathrm{x}} \mathrm{Ge}_{\mathrm{x}}$ nanostructures, the dependence is stronger; $\omega_{G e-G e} \approx 280+35 x$.

(c) In bulk $\mathrm{Si}_{1-\mathrm{x}} \mathrm{Ge}_{\mathrm{x}}$ alloys, the $\mathrm{Si}-\mathrm{Ge}$ Raman peak wavenumber increases for $\mathrm{x}<0.6$ and decreases for $\mathrm{x}>0.6$. However, in $\mathrm{Si} / \mathrm{Si}_{1-\mathrm{x}} \mathrm{Ge}_{\mathrm{x}}$ nanostructures the dependence can be described as $\omega_{S i-G e} \approx 400+30 x$

The results presented here indicate that apart from average composition $\mathrm{x}$ of $\mathrm{Si} / \mathrm{Si}_{1-\mathrm{x}} \mathrm{Ge}_{\mathrm{x}}$ nanostructures other factors such as layer thicknesses, SiGe island sizes, shapes and local strain should be to be taken into account in analyzing the dependencies of the Raman peaks. The most common explanation is that an accumulation of Ge in the middle of planar layers and within the SiGe island core is responsible for a non-uniform composition and strain distribution. Possible detailed mechanisms are: the out diffusion of Ge and formation of compressed Si rich alloy regions in the valleys of the $\mathrm{Si}_{1-\mathrm{x}} \mathrm{Ge}_{\mathrm{x}}$ island multilayers, strong diffusion coefficient dependence on the local Ge concentration in the film, and the tensile strain in the Si spacer layer on the top of the SiGe islands $[19,20]$.

In $\mathrm{Si} / \mathrm{SiGe}$ periodic nanostructures, multiple Raman peaks at the low wavenumbers $\left(<100 \mathrm{~cm}^{-1}\right)$ are associated with folding of longitudinal acoustic (FLA) phonons due to the growth introduced new periodicity $P_{S L}$ and formation of the Brillouin mini-zone. A commonly used method for the calculation of phonon dispersion curves is to use the elastic continuum model by Rytov [21]. One of the conditions of this model is that the wavelength of the sound wave should be much larger than the layer thickness. The elastic continuum approximation is then valid and the wave equation in each layer can be solved. Figure 6a shows the low-frequency Raman spectrum in a $\mathrm{Si} / \mathrm{SiGe} \mathrm{SL}$ (shown in Fig. 1a) with distinct Raman doublets corresponding to various FLA modes. The inset shows a simplified FLA phonon dispersion diagram based on Rytov's model. In reality, band gaps appear at the mini-zone center and boundary (Fig. 6b) due to the difference in the acoustic impedances of the two component layers of the SL [22]. These gaps are barriers to phonon propagation along the SL growth direction and having the appropriate energies and 
wave vectors. Thus, these $\mathrm{Si} / \mathrm{SiGe}$ periodic nanostructures are the first known examples of onedimensional phononic crystals [15].

\section{Second order Raman scattering in $\mathrm{Si} / \mathrm{SiGe}$ nanostructures}

In $\mathrm{Si} / \mathrm{SiGe}$ nanostructures, Raman peaks associated with second-order light scattering are observed between 550 and $1100 \mathrm{~cm}^{-1}$ (Fig. 11). The two-transverse optical (2TO) Si phonon overtone features are related to scattering from the Brillouin zone critical points at $\mathrm{W}$ and $\mathrm{L}$, and they are found at 940 and $975 \mathrm{~cm}^{-1}$, respectively $[23,24]$. The 2TO Raman signal is actually comprised of three peaks: the major Raman peak associated with scattering from 2TO(L) phonons, the $2 \mathrm{TO}(\mathrm{W})$ Raman peak, and a weak shoulder associated with the $2 \mathrm{TO}(\Gamma)$ phonon. In most of the $\mathrm{Si} / \mathrm{SiGe}$ nanostructures we investigated, we also found strong Raman features associated with second order Si-Ge vibrations around $800 \mathrm{~cm}^{-1}$ and second order Ge-Ge vibrations at $\sim 600 \mathrm{~cm}^{-1}$. Also, other weaker Raman features at $\sim 680 \mathrm{~cm}^{-1}$ and in the range of $840-900 \mathrm{~cm}^{-1}$ are, most likely, overtones of the first-order Ge-Ge (in the presence of Si) and local $\mathrm{Si}-\mathrm{Si}$ (in the presence of Ge) modes [24].

\section{Strain and chemical composition in $\mathrm{Si} / \mathrm{Si}_{1-x} \mathbf{G e}_{x}$ nanostructures}

In $\mathrm{Si} / \mathrm{Si}_{1-\mathrm{x}} \mathrm{Ge}_{\mathrm{x}}$ nanostructures, a correlation between $\mathrm{Si}-\mathrm{Si}$, $\mathrm{Si}-\mathrm{Ge}$ and $\mathrm{Ge}-\mathrm{Ge}$ Raman peak positions, Ge content $x$ and strain $\varepsilon$ has been extensively discussed [19, 20, 25]. The relative number of chemical bonds comprising the $\mathrm{Si}-\mathrm{Si}, \mathrm{Si}-\mathrm{Ge}$, and $\mathrm{Ge}-\mathrm{Ge}$ phonon modes are estimated as $(1-x)^{2}, 2 x(1-x)$, and $x^{2}$, respectively. Since the Raman signal is proportional to the scattered volume, the ratio of the integrated Raman peak intensities related to the relative number of chemical bonds of the corresponding phonon modes can be described as follows:

$$
\begin{aligned}
& I_{G e G e} / I_{S i G e}=B x / 2(1-x), \\
& I_{S i S i} / I_{S i G e}=A(1-x) / 2 x,
\end{aligned}
$$

where coefficients $A$ and $B$ are related to the frequencies of the optical modes in the SiGe alloy. It was found experimentally that $B=3.2$ and $A=1.85$ for $458 \mathrm{~nm}$ excitation [26]. The so-called 
intensity method for determining the value of $x$ is independent of strain in the alloy layer and depends on the integrated intensity of the Raman signal associated with the phonon bands. In the Raman peak position (the wavenumber method), a set of equations is used, where the peak position of the three major vibrational modes in $\mathrm{Si} / \mathrm{Si}_{1-x} \mathrm{Ge}_{x}$ nanostructures is described as a function of $x$ and $\varepsilon$. The frequency of the phonon band can be expressed as:

$$
\omega=\omega_{0}+b \varepsilon,
$$

where $\omega_{0}$ is the $x$ dependent phonon frequency of the unstrained SiGe alloy and $b$ is the strainshift coefficient. In the case of a strained $\mathrm{Si}_{1-x} \mathrm{Ge}_{x}(0<x<0.5)$ layer, the wavenumbers of the three different phonon modes, according to Refs. [25, 26], are:

$$
\begin{aligned}
& \omega_{S i-S i}=520.2-70.5 x-830 \varepsilon, \\
& \omega_{S i-G e}=400.5+16.3 x-575 \varepsilon, \\
& \omega_{G e-G e}=282.5+16 x-384 \varepsilon .
\end{aligned}
$$

The average values of $x$ and $\varepsilon$ in the alloy layer are

$$
x=\frac{\left(\omega_{S i-G e}-400\right)-\left(0.7 \times\left(\omega_{S i-S i}-520\right)\right)}{65},
$$

and

$$
\varepsilon=\frac{\left(400-\omega_{S i-G e}\right)+0.23 \times\left(520-\omega_{S i-S i}\right)}{767} .
$$

Considering published data $[9,19,20]$, we find a reasonably good agreement between both methods.

\section{Raman studies of thermal conductivity and heat dissipation in $\mathrm{Si} / \mathrm{Si}_{1-\mathrm{x}} \mathbf{G e}_{\mathrm{x}}$ nanostructures}

Typically, Raman scattering measurements are performed using an intense laser radiation. While c-Si and c-Ge have high thermal conductivity $k \approx 100 \mathrm{Wm}^{-1} \mathrm{~K}^{-1}$, in compositionally disordered $\mathrm{SiGe}$ alloys and $\mathrm{Si} / \mathrm{SiGe}$ nanostructures $k \leq 10 \mathrm{~W} \mathrm{~m}^{-1} \mathrm{~K}^{-1}$ [27]. Thus, a significant temperature increase of a sample might occur during Raman scattering measurements and it will affect the 
Raman peak position, width and line shape. Using a model based on the Fourier law of heat conduction, the thermal conductivity can be calculated as

$$
\kappa=P^{*}(L / A)^{*}(1 / \Delta T),
$$

where $P$ is the laser power absorbed by a sample with a thickness $L$ in the direction normal to a surface of a cross-sectional area $A$ due to a temperature gradient $\Delta T$. The temperature gradient is established between the highest temperature at the sample surface and the lowest temperature of the c-Si substrate (due to the high c-Si thermal conductivity), and these temperatures can be calculated using the Stokes/anti-Stokes Raman peak intensity ratio for strained $\mathrm{Si}$ and $\mathrm{Si}-\mathrm{Ge}$ phonon modes and the $\mathrm{Si}-\mathrm{Si}$ mode at $520 \mathrm{~cm}^{-1}$ (assuming that it is associated with the c-Si substrate). In measured samples, the calculated thermal conductivity is $\sim 12 \mathrm{~W} \mathrm{~cm}^{-1} \mathrm{~K}^{-1}$ for $\mathrm{Si} / \mathrm{Si} / \mathrm{SiGe} \mathrm{SLs}$ and is $\sim 4 \mathrm{~W} \mathrm{~cm}^{-1} \mathrm{~K}^{-1}$ in $\mathrm{Si} / \mathrm{SiGe} \mathrm{CMs}$ respectively. The reason for the lower thermal conductivity found in $\mathrm{Si} / \mathrm{SiGe} \mathrm{CMs}$ compared to $\mathrm{Si} / \mathrm{SiGe} \mathrm{SLs}$ can be explained by analyzing a comparative volume fraction of $\mathrm{SiGe}$ (a lower thermal conductivity material) versus c-Si (a higher thermal conductivity material) and quality of the $\mathrm{Si} / \mathrm{SiGe}$ heterointerfaces. We find that typically in $\mathrm{Si} / \mathrm{SiGe} \mathrm{CMs}$, the volume fraction of $\mathrm{SiGe}$ is nearly twice that of $\mathrm{Si} / \mathrm{SiGe} \mathrm{SLs}$, and inelastic scattering of phonons in $\mathrm{Si} / \mathrm{SiGe}$ nanostructures with a diffuse interface also contributes to the reduction in thermal conductivity [28]. It was also reported that the temperature calculated according to Boltzmann statistics under a non-resonant condition of the Ge-Ge phonon mode is consistently lower than that found for the Si-Ge and Si-Si modes [27]. This discrepancy can be explained assuming that for the used laser excitation wavelengths, the Ge-Ge phonon mode has a resonant component, as it was pointed out in Refs. 9, 29, 30.

\section{Polarization dependent Raman scattering in $\mathrm{Si} / \mathrm{SiGe}$ nanostructures}

Polarized Raman scattering provides information on the Raman scattering intensity as a function of the polarization angle of the scattered light [12-14]. The particular shape of the polar plot depends on the symmetry of the vibrational mode being measured and the crystallographic orientation of the sample. Figure 8 shows angular Raman polarization diagrams for three different vibrational modes ( $\mathrm{Si}-\mathrm{Si}$ at $520 \mathrm{~cm}^{-1}$, Si-Ge at $415 \mathrm{~cm}^{-1}$, and $\mathrm{Ge}-\mathrm{Ge}$ at $298 \mathrm{~cm}^{-1}$ ) for $\mathrm{Si} / \mathrm{SiGe} \mathrm{S}-\mathrm{K} \mathrm{CM}$ samples [12]. The observed angular dependencies of the $\mathrm{Ge}-\mathrm{Ge}$ and $\mathrm{Si}-\mathrm{Ge}$ 
Raman mode intensities are nearly identical to that measured in a (100) Si single crystal (solid line). However, a quite different behavior is observed in the Raman polarization dependence for the Si-Si Raman mode at 520. The observed deviation is explained by strain-induced partial relaxation of selection rules, mixing of different phonon modes in the nanometer-thick Si layers separating the SiGe cluster layers and, possibly, in a thin layer of the c-Si substrate directly under the sample. The strong localization of strain observed in the Si layers is consistent with the understanding of the nature of vertical self-ordering produced by strain propagation in $\mathrm{Si} / \mathrm{SiGe} \mathrm{S}$ K CM nanostructures. Similar measurements performed in Si/SiGe SL samples did not reveal any deviation from the data obtained in (100) c-Si substrates.

\section{Conclusion}

In conclusion, this review of the various phenomena associated with first- and second-order inelastic light scattering in Si/SiGe SLs and S-K CMs provides an analysis of the Raman spectrum dependence on strain and chemical composition, discusses low-wavenumber Raman scattering associated with folded acoustic phonon modes in periodic Si/SiGe nanostructures and analyzes a laser-induced sample temperature increase during Raman scattering measurements. The results presented here are important for the development of practical quantitative and nondestructive metrological procedures for a wide variety of SiGe based nanoscale electronic, photonic, and thermoelectric devices. At the same time, we do not discuss in this work several specific techniques such as surface- and tip-enhanced Raman scattering [31] and non-linear Raman scattering [32-33]. We think that these important phenomena require detailed consideration and should be covered in a separate review.

\section{Acknowledgements}

We thank our many co-workers and colleagues who have contributed over the last three decades to the Raman studies of SiGe nanostructures, and in particular H.J. Labbé, X. Wu, S. Moisa, and J.P. McCaffrey of the National Research Council, and H.K. Shin. L. Tsybeskov would like to acknowledge support by the Foundation at NJIT, Intel, Hewlett-Packard Laboratories and NSF Award 1027770. 


\section{Figure Captions}

Figure 1. Cross-sectional transmission electron micrograph (TEM) images of (a) an MBE grown planar $\mathrm{Si} / \mathrm{Si}_{0.65} \mathrm{Ge}_{0.35}$ superlattice and (b) a $\mathrm{Si} / \mathrm{SiGe}$ cluster multilayer nanostructures.

Figure 2. Raman spectrum of a Si/Si $i_{1-x} \mathrm{Ge}_{\mathrm{x}}$ superlattice (see TEM image on Fig. 1) showing peaks associated with Si first-order central zone optical phonons $\left(520 \mathrm{~cm}^{-1}\right)$, strained Si $(\sim 505$ $\left.\mathrm{cm}^{-1}\right)$, Si-Ge $\left(\sim 400 \mathrm{~cm}^{-1}\right)$ and Ge-Ge $\left(\sim 300 \mathrm{~cm}^{-1}\right)$. Raman spectrum of c-Si is shown for comparison. Note logarithmic vertical scale.

Figure 3. Raman spectrum in a $\mathrm{Si} / \mathrm{Si}_{1-\mathrm{x}} \mathrm{Ge}_{\mathrm{x}}$ cluster multilayer cluster multilayer nanostructure with $\mathrm{x} \approx 0.5$ with the Raman peak at $\sim 490 \mathrm{~cm}^{-1}$ attributed to the local Si-Si vibration mode in the presence of $\mathrm{Ge}$, or $\mathrm{Si}-\mathrm{Si}$ measured using $458 \mathrm{~nm}$ and $514 \mathrm{~nm}$ excitation wavelengths. Note vertical logarithmic scale and Raman peaks at 520, 508 and $490 \mathrm{~cm}^{-1}$ under $514 \mathrm{~nm}$ excitation.

Figure 4. Raman spectra associated with Si-Ge and Ge-Ge vibrations at $417-418 \mathrm{~cm}^{-1}$ and 298$299 \mathrm{~cm}^{-1}$ in Si/SiGe Stranski-Krastanov cluster multilayers (S-K CM) and planar superlattices (SL).

Figure 5. A summary of the reported dependencies of the Raman peak wavenumbers associated with $\mathrm{Si}-\mathrm{Si}, \mathrm{Si}-\mathrm{Ge}$ and $\mathrm{Ge}-\mathrm{Ge}$ vibrations on the composition $\mathrm{x}$ in (a) bulk $\mathrm{Si}_{1-\mathrm{x}} \mathrm{Ge}_{\mathrm{x}}$ alloys and (b) SiGe nanostructures with various degree of strain. For details, see Ref. 19.

Figure 6. (a) Raman spectra at the low wavenumbers in $\mathrm{Si} / \mathrm{Si}_{0.65} \mathrm{Ge}_{0.35}$ superlattices. The acoustic phonon peaks appear in pairs in accordance with their zone folding index $\mathrm{m}$. The inset shows a schematic of the formation of the Brillouin mini-zone and the anticipated peak positions due to Raman interactions with folded longitudinal acoustic (FLA) phonons for this sample; (b) The measured points and dispersion relation (dashed lines) of the FLA phonons near the mini-zoneedge band gap arising from the difference in the acoustic impedances of the two component layers of the $\mathrm{Si} / \mathrm{Si}_{0.5} \mathrm{Ge}_{0.5}$ SL. For further details, see Ref. [15]. 
Figure 7. Details of the second order Raman scattering in c-Si and a $\mathrm{Si} / \mathrm{SiGe}$ suprlattice involving optical phonons at $550-1150 \mathrm{~cm}^{-1}$.

Figure 8. Angular Raman polarization diagrams for $\mathrm{Si}-\mathrm{Si}, \mathrm{Si}-\mathrm{Ge}$, and $\mathrm{Ge}-\mathrm{Ge}$ vibrational modes for a $\mathrm{Si} / \mathrm{SiGe}$ Stranski-Krastanov cluster multilayers sample measured using $458 \mathrm{~nm}$ laser excitation. A (100) Si single crystal measured Raman polarization diagram is shown for comparison. 


\section{References}

1. F. Cerdeira, A. Pinczuk, J. C. Bean, B. Batlogg, and B. A. Wilson, Appl. Phys. Lett. 45 (1984) 1138.

2. J. L. Liu, Y. S. Tang, K. L. Wang, T. Radetic, and R. Gronsky, Appl. Phys. Lett. 74 (1999) 1863.

3. E. G. Barbagiovanni, D. J. Lockwood, P. J. Simpson, L. V. Goncharova, J. Appl. Phys. $111(2012) 034307$.

4. J. Menéndez, A. Pinczuk, J. Bevk, J. P. Mannaerts, Journ. Vac. Sc. Techn. B 6 (1988) 1306.

5. B. V. Kamenev, L. Tsybeskov, J.-M. Baribeau, D. J. Lockwood, Appl. Phys. Lett. 84 (2004) 1293.

6. M. Cardona, Y. Y. Peter, Fundamentals of semiconductors. Springer-Verlag Berlin Heidelberg (2005) 619.

7. M. I. Alonso, K. Winer, Physical Review B 39 (1989) 10056.

8. P. M. Mooney, F. H. Dacol, J. C. Tsang, J. O. Chu, Appl. Phys. Lett. 62 (1993) 2069.

9. S. A. Mala, L. Tsybeskov, D. J. Lockwood, X. Wu, X., and J. M. Baribeau, J. Appl. Phys., 116, (2014) 014305.

10. F. Cerdeira, M. I. Alonso, D. Niles, M. Garriga, M. Cardona, E. Kasper, H. Kibbel, Phys. Rev. B 40 (1989) 1361.

11. M. Cazayous, J. R. Huntzinger, J. Groenen, A. Mlayah, S. Christiansen, H. P. Strunk, O. G. Schmidt, and K. Eberl, Phys. Rev. B 62 (2000) 7243.

12. B. V. Kamenev, H. Grebel, L. Tsybeskov, T. I. Kamins, R. S. Williams, J.-M. Baribeau, D. J. L. Lockwood. Appl. Phys. Lett. 83 (2003) 5035.

13. M. Mermoux, A. Crisci, F. Baillet, V. Destefanis, D. Rouchon, A. M. Papon, J. M. Hartmann, J. Appl. Phys. 107 (2010) 013512.

14. A. V. Baranov, A. V. Fedorov, T. S. Perova, R. A. Moore, V. Yam, D. Bouchier, V. Le Thanh, K. Berwick, Phys. Rev. B 73 (2006) 075322.

15. D. Zhang, D. J. Lockwood, H. J. Labbé, and J.-M. Baribeau. Phys. Rev. B 46 (1992) 9881.

16. D. J. Eaglesham, M. Cerullo, Phys. Rev. Lett. 64 (1990) 1943. 
17. F. M. Ross, J. Tersoff, R. M. Tromp. Phys. Rev. Lett. 80 (1998) 984.

18. J. A. Floro, E. Chason, L. B. Freund, R. D. Twesten, R. Q. Hwang, and G. A. Lucadamo. Phys. Rev. B 59 (1999) 1990.

19. H. K. Shin, D. J. Lockwood, and J. M. Baribeau, Solid State Commun., 114, (2000) 505.

20. D. J. Lockwood and J.-M. Baribeau, "Characterization of Strain and Epitaxial Quality in $\mathrm{Si} /$ Ge Heterostructures," in Light Scattering from Semiconductor Structures and

Superlattices (D.J. Lockwood and J.F. Young, Eds.), Plenum, New York, (1991) 197.

21. S. M. Rytov, Sov. Phys. Acoust. 2 (1956) 68.

22. D. Zhang, D. J. Lockwood, H. J. Labbé, and J.-M. Baribeau. Phys. Rev. B 46 (1992) 9881.

23. P. A. Temple and C. E. Hathaway, Phys. Rev. B 7 (1973) 3685.

24. J. S. Lannin, Phys. Rev. B 16 (1977) 1510.

25. T. S. Perova, J. Wasyluk, K. Lyutovich, E. Kasper, M. Oehme, K. Rode, and A. Waldron, J. Appl. Phys. 109 (2011) 033502.

26. P. M. Mooney, F. H. Dacol, J. C. Tsang, and J. O. Chu, Appl. Phys. Lett. 62 (1993) 2069.

27. H.-Y. Chang and L. Tsybeskov, in Silicon Nanocrystals: Fundamentals Synthesis and applications, ed. L. Pavesi, R. Turan, Wiley-VCH, Weinheim, 2010, p. 105.

28. G. Chen, Phys. Rev. B 57 (1998) 14958.

29. K. Brunner, Reports on Progress in Physics 65 (2001) 27.

30. R. Schorer, G. Abstreiter, H. Kibbel, H. Presting, C. Tserbak, and G. Theodorou, Solid State Comm. 93, (1995) 1025.

31. Y. Saito, M. Motohashi, N. Hayazawa, M. Iyoki, and S. Kawata, S. (2006). Appl. Phys. Lett. 88 (2006) 143109.

32. R. Claps, V. Raghunathan, D. Dimitropoulos, and B. Jalali, B. (2004). Opt. Expr. 12 (2004) 2774.

33. H. Rong, A. Liu, R. Jones, O. Cohen, D. Hak, R. Nicolaescu, A. Fang, and M. Paniccia, Nature 433 (2005) 292. 


\section{FIGURES}

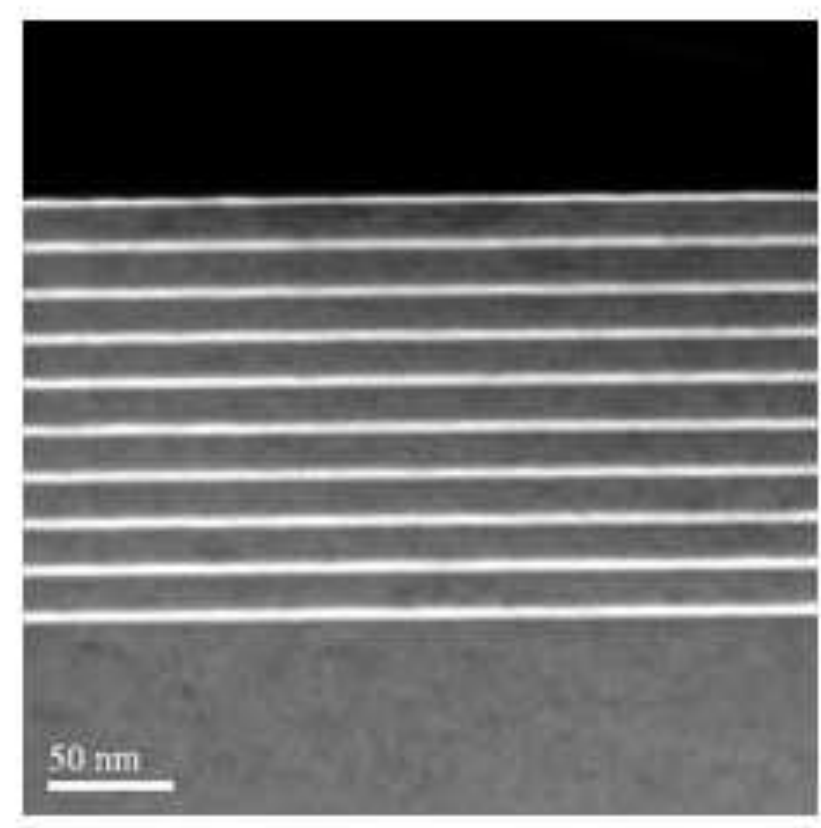

(a)

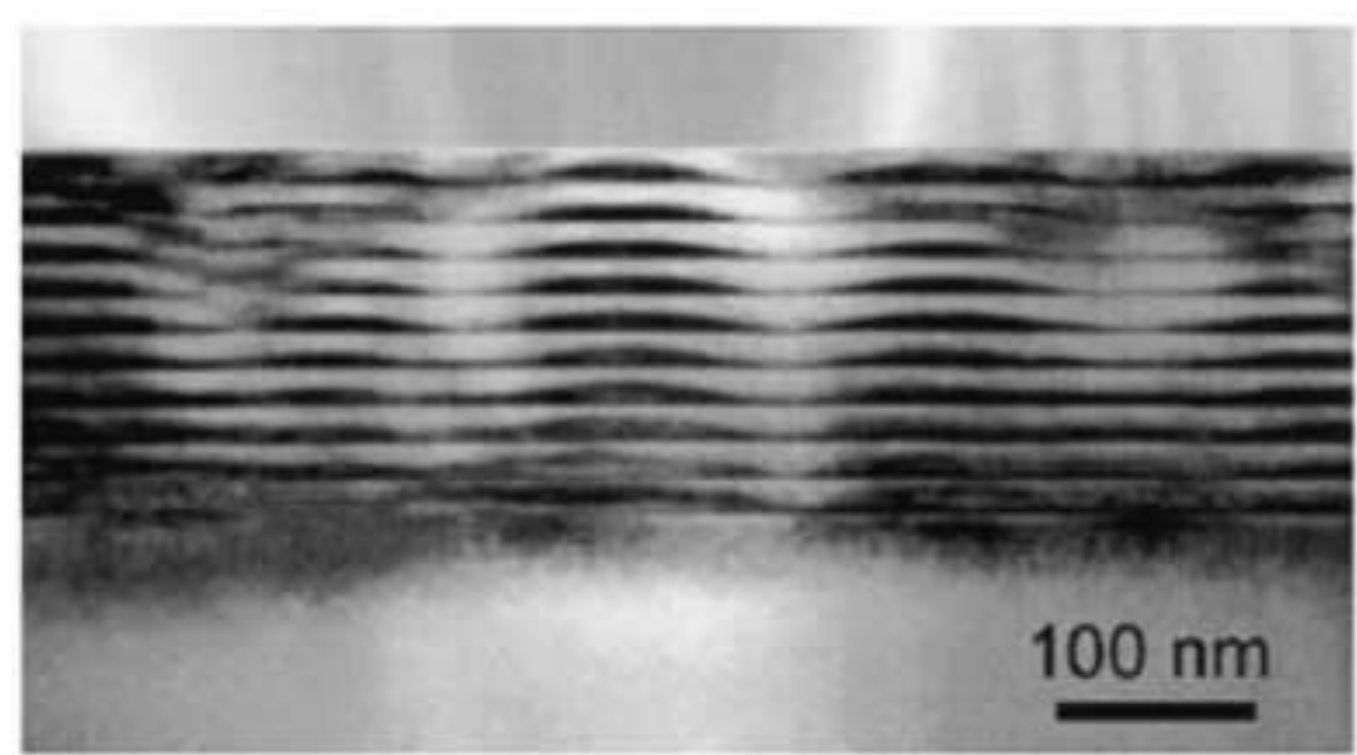

(b)

Tsybeskov et al., Fig. 1 


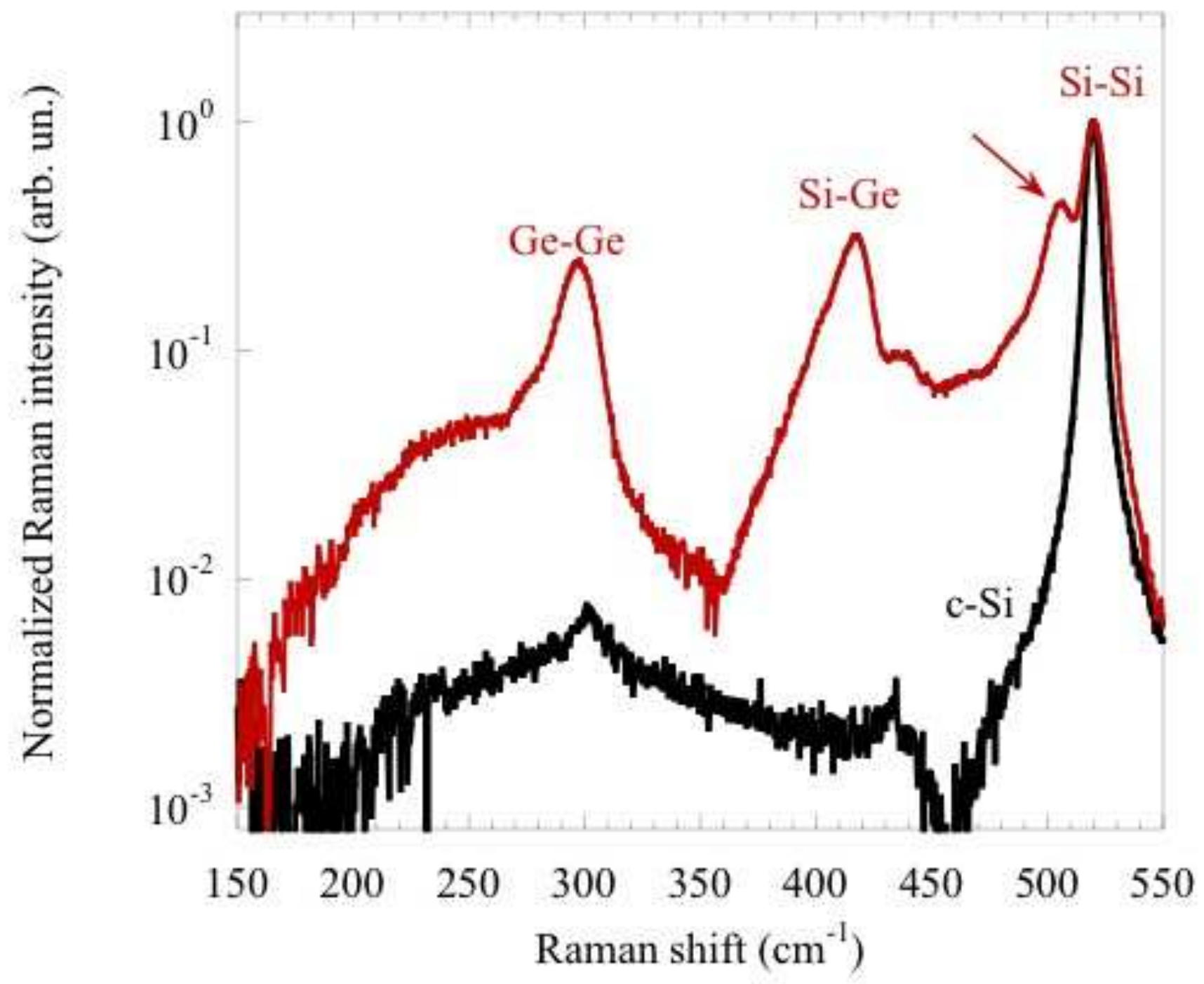

Tsybeskov et al., Fig. 2 


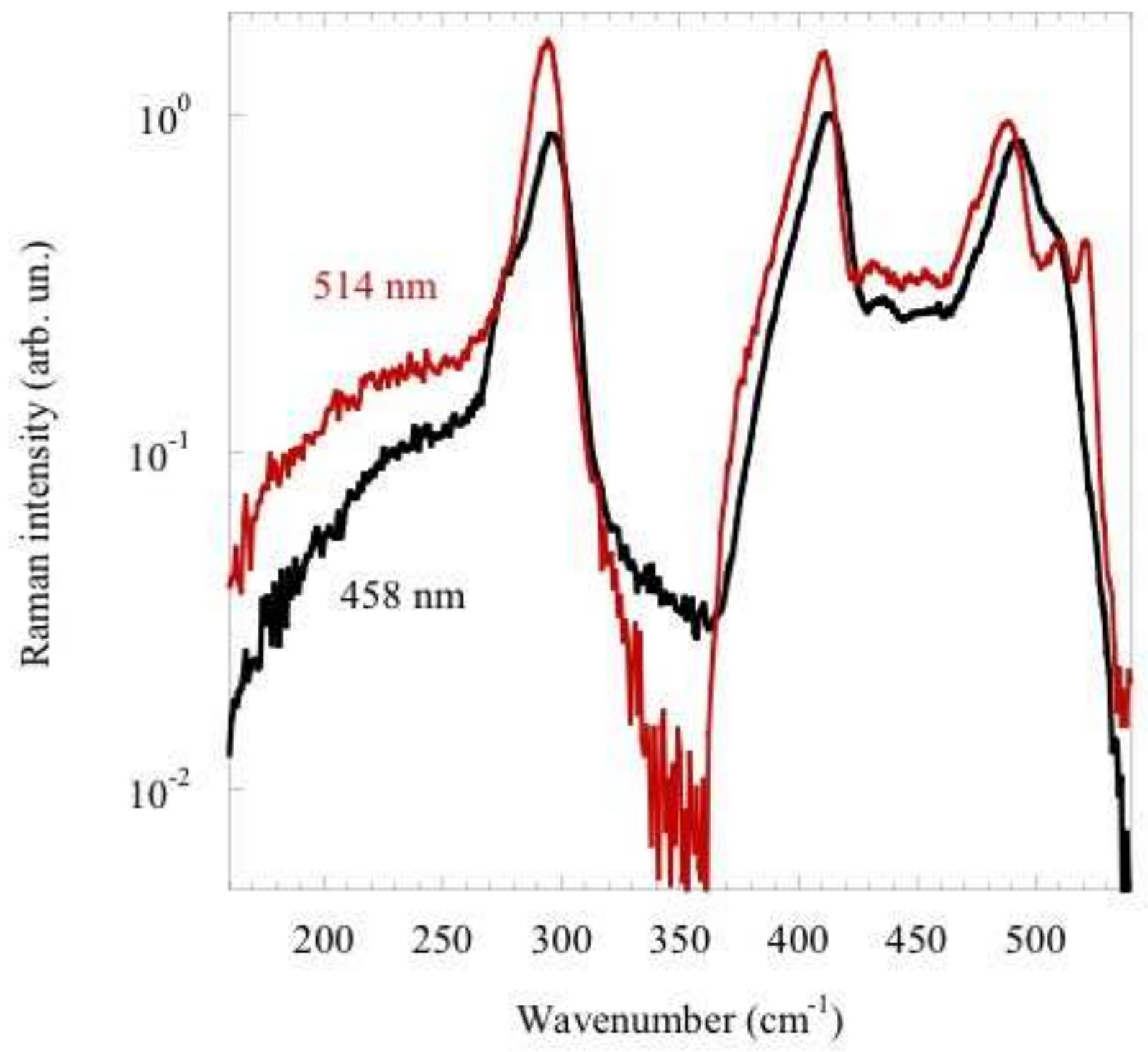

Tsybeskov et al., Fig. 3 


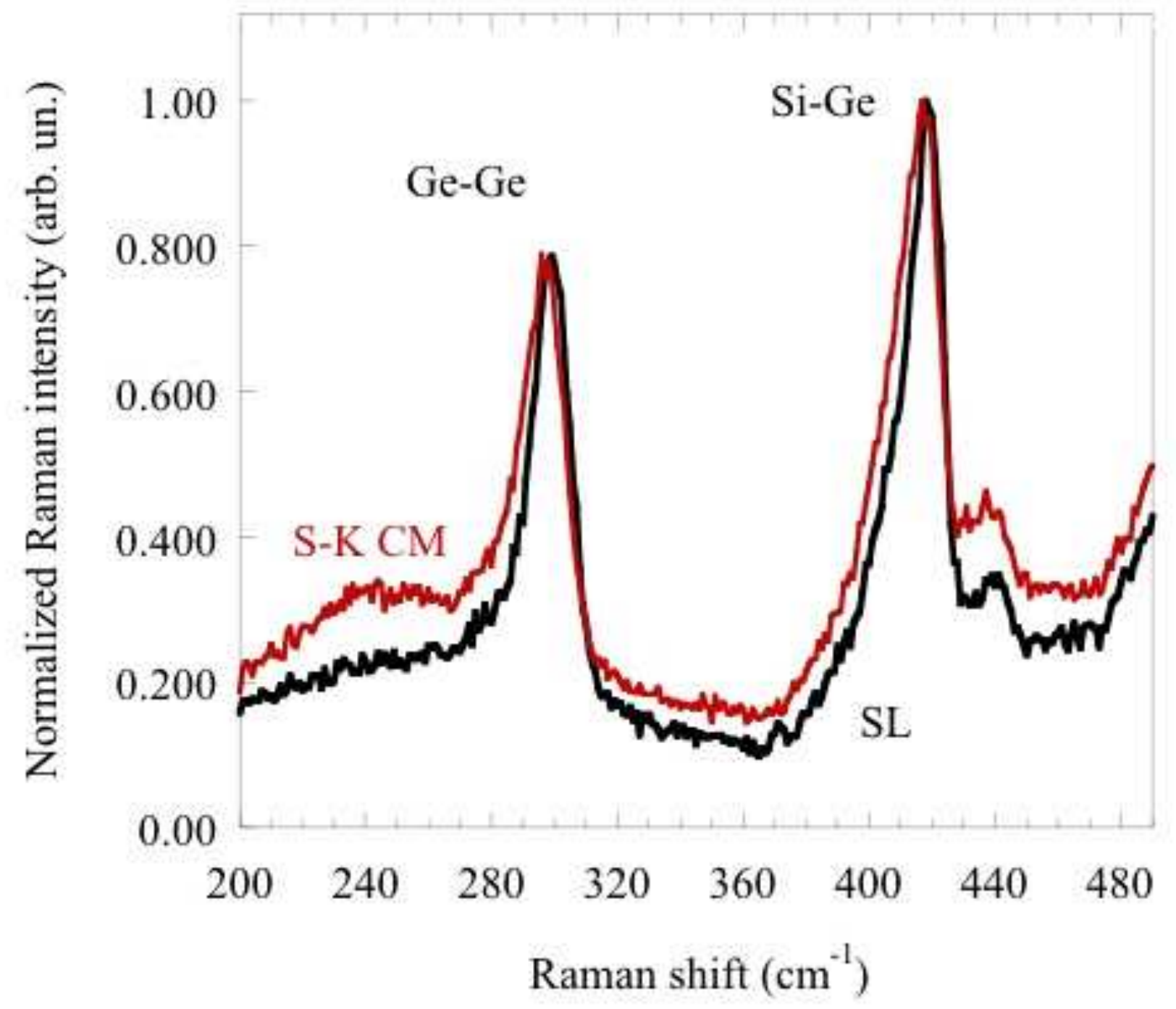

Tsybeskov et al., Fig. 4 


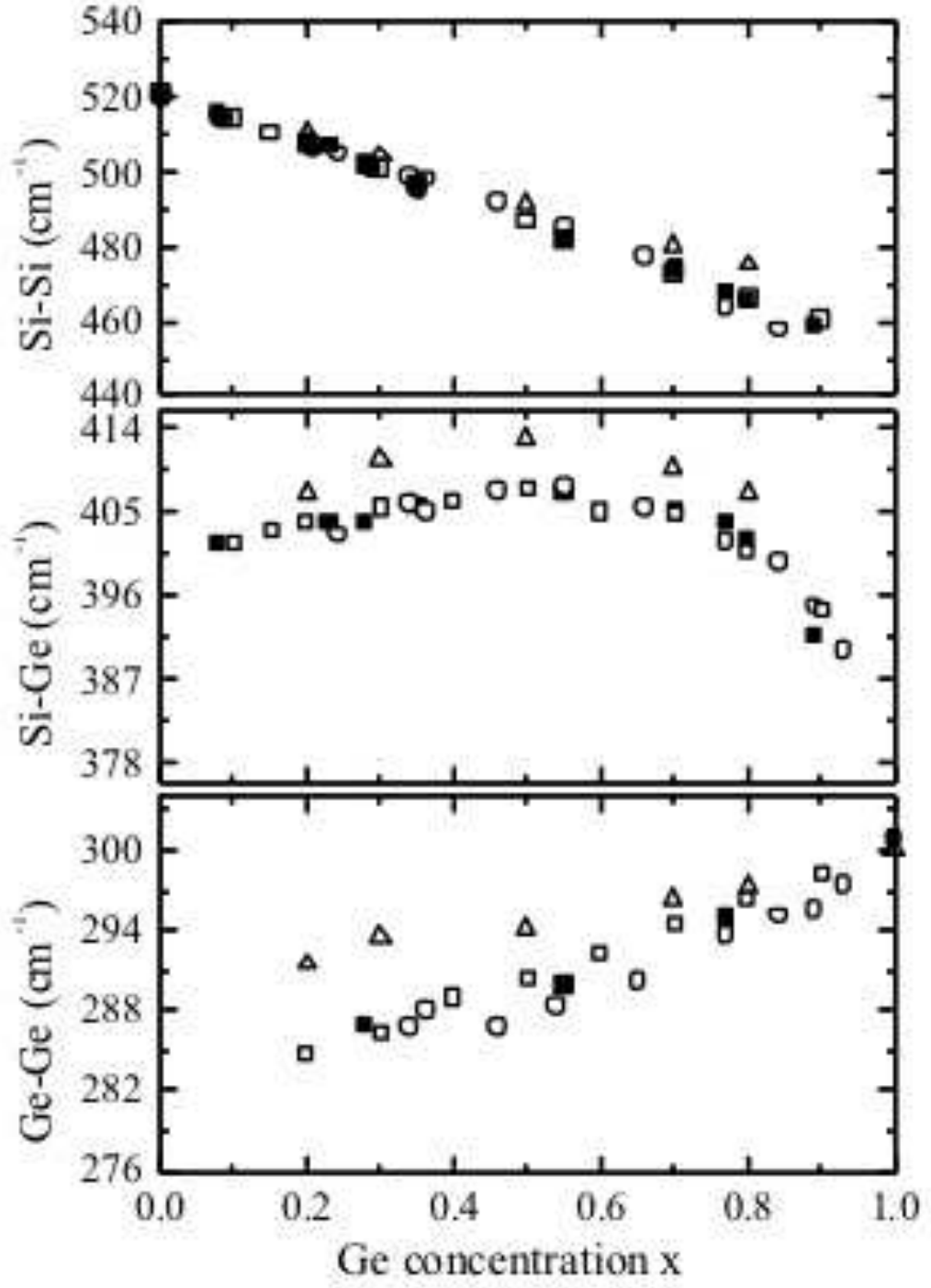

(a)

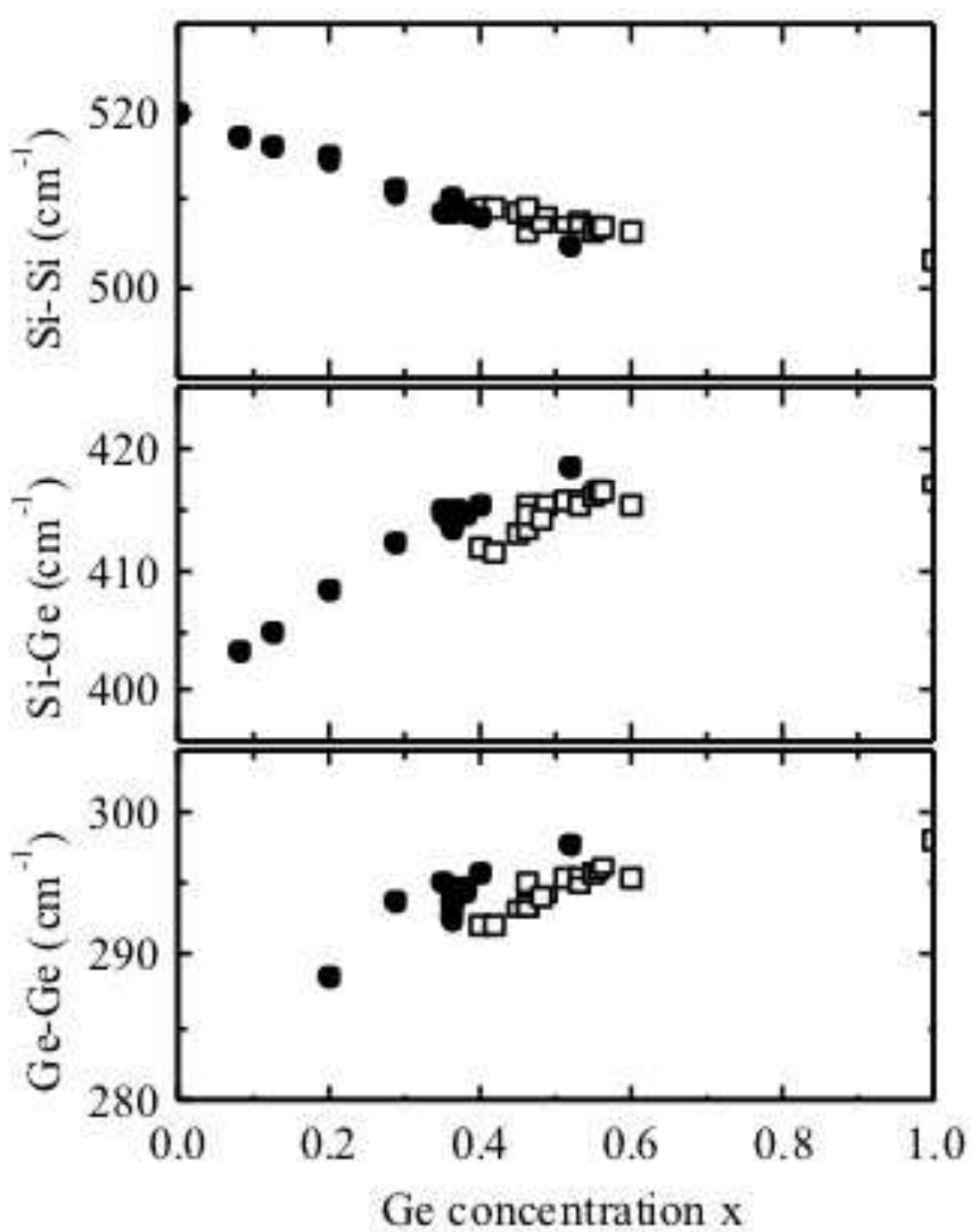

(b)

Tsybeskov et al., Fig. 5 


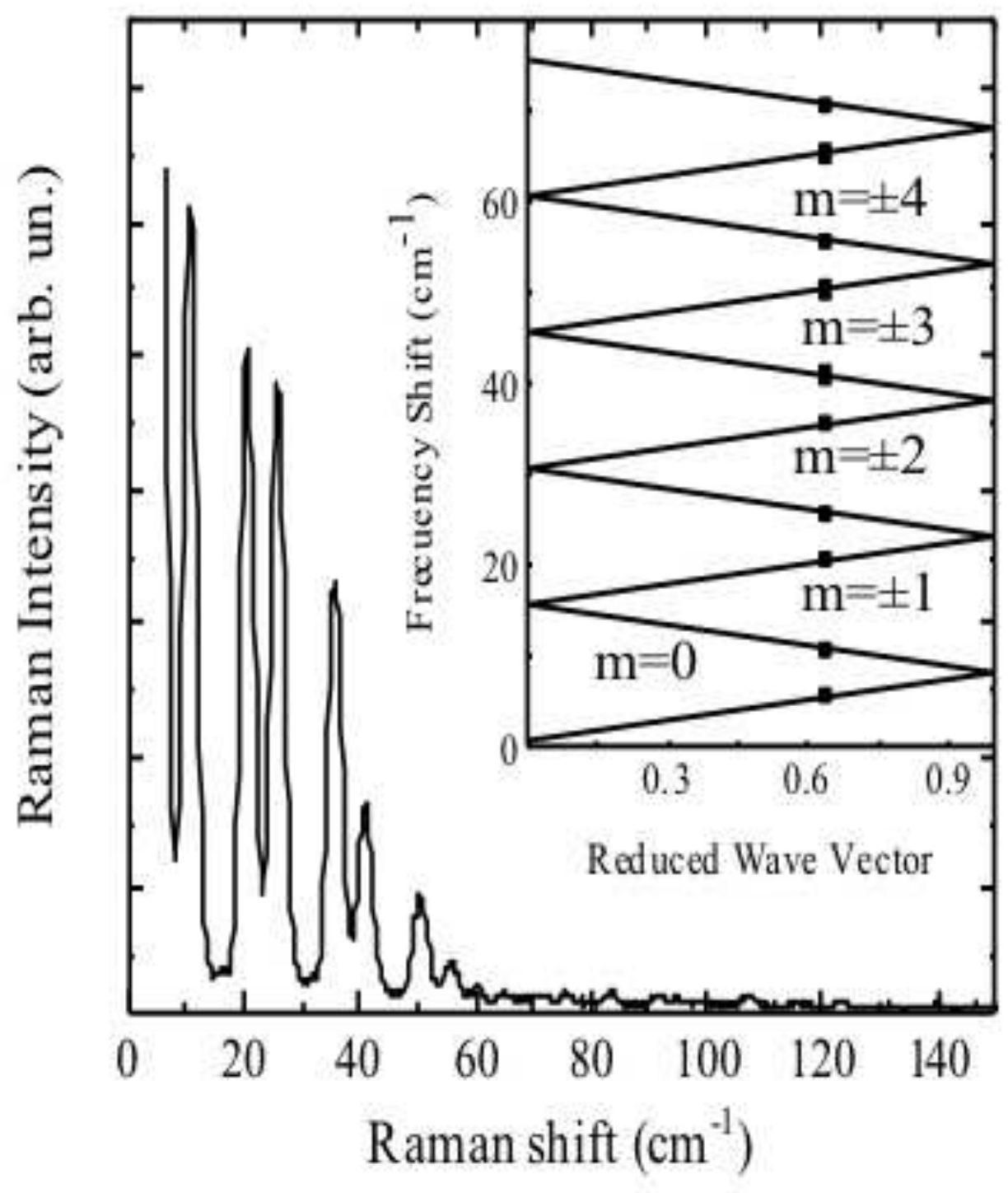

(a)

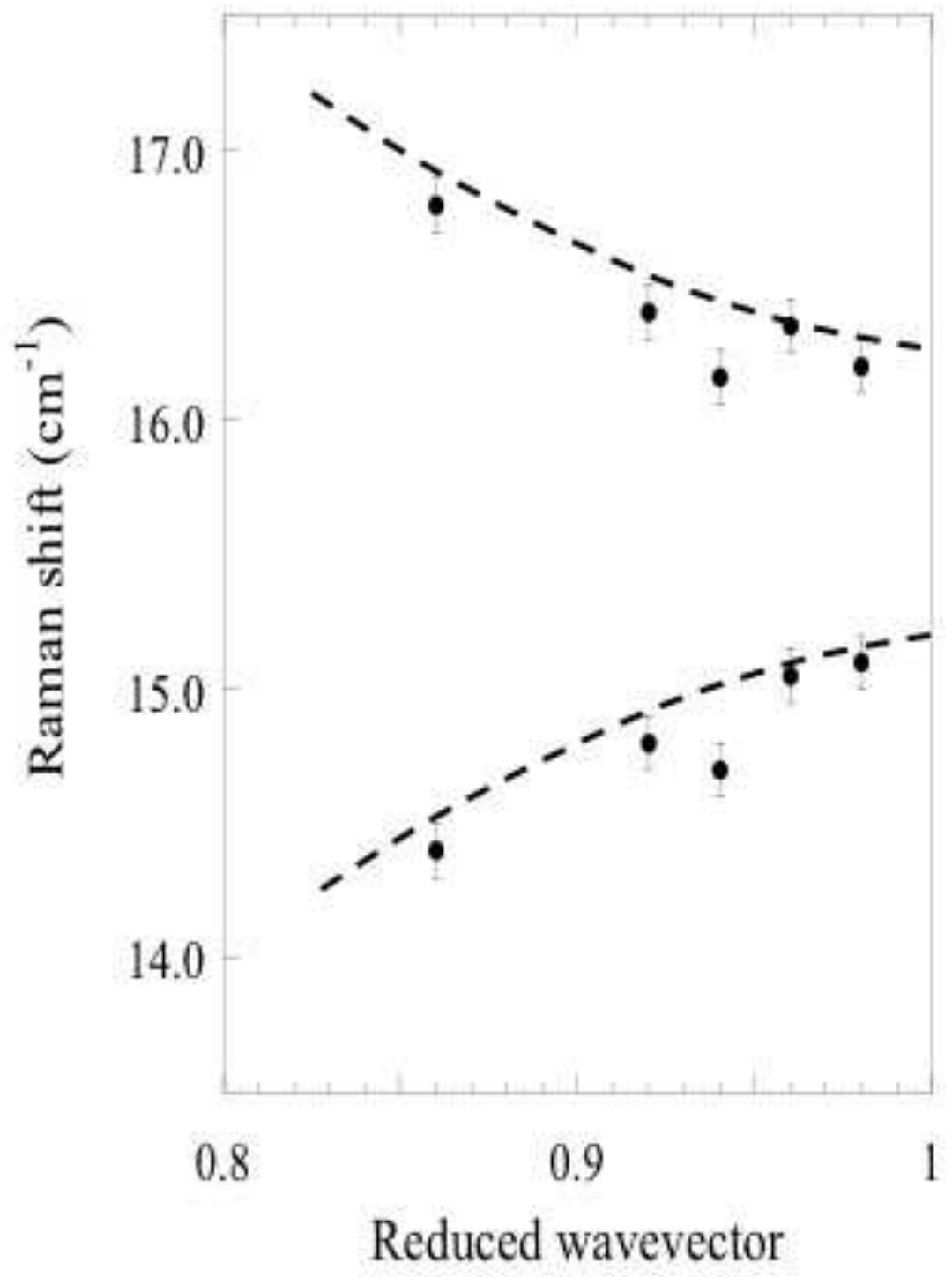

(b)

Tsybeskov et al., Fig. 6 


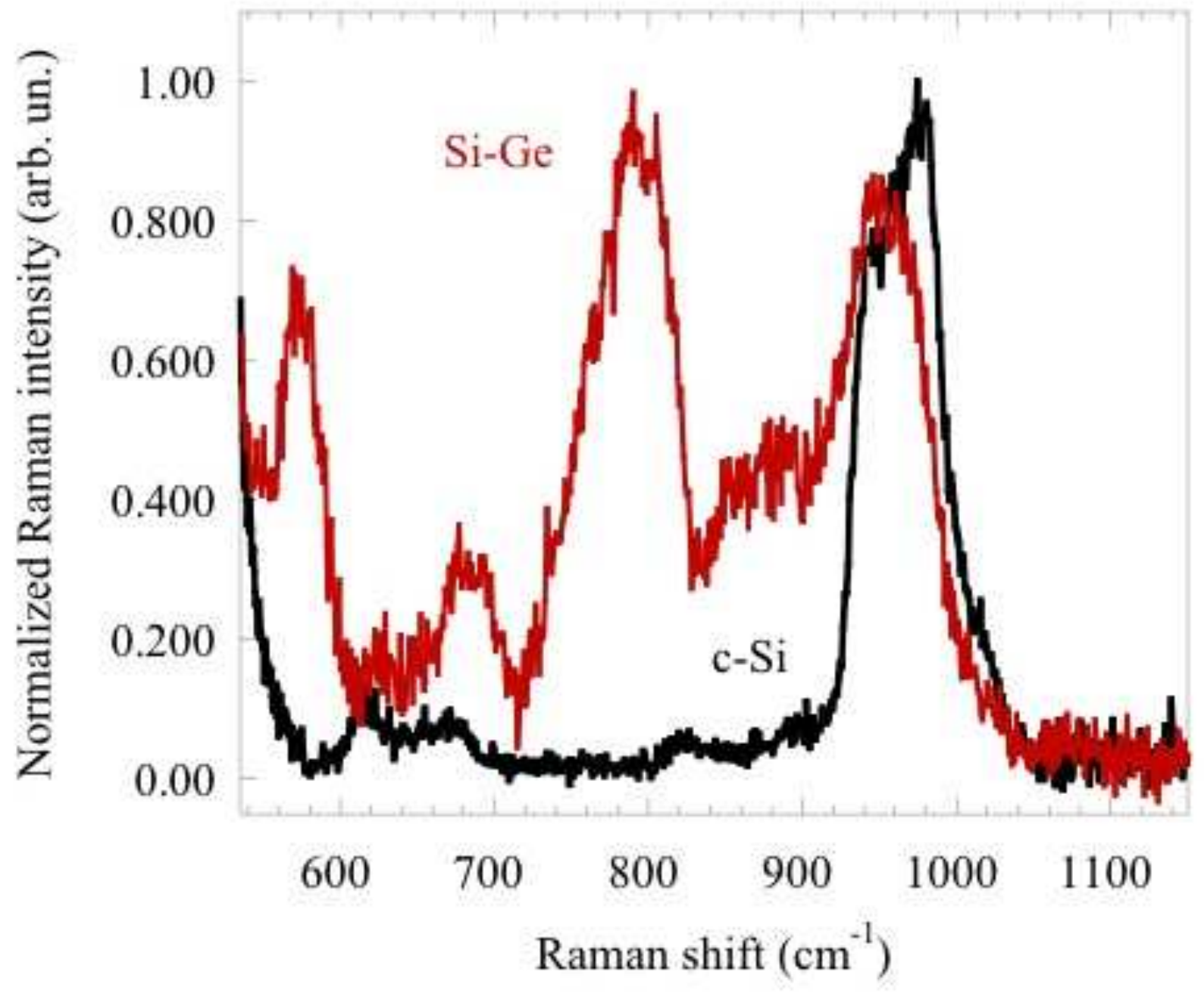

Tsybeskov et al., Fig. 7 


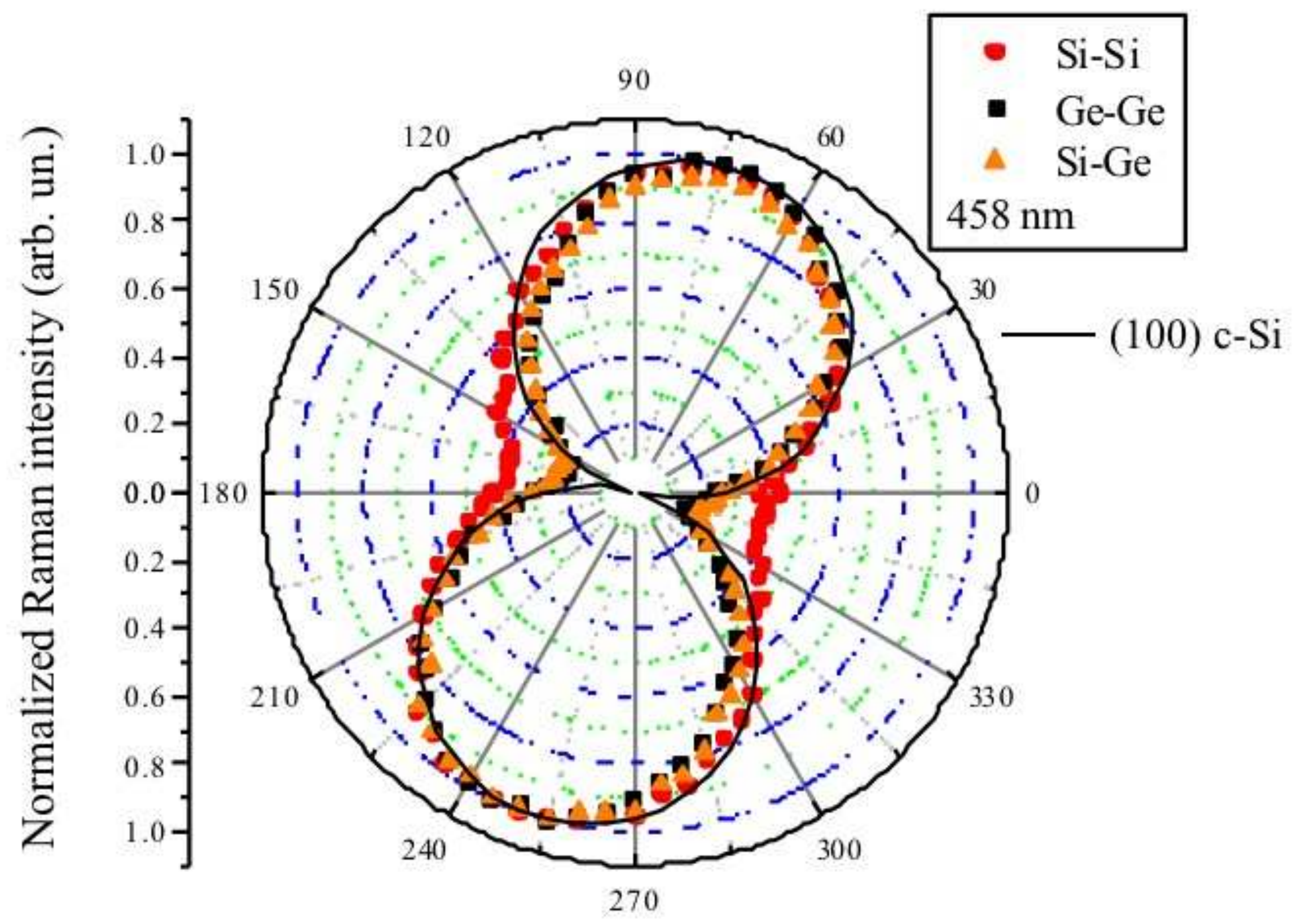

Tsybeskov et al., Fig. 8 